\title{
O CONCEITO DE “ÁGUA VIRTUAL” SOB O ENFOQUE DA DIVISÃO INTERNACIONAL DOS RISCOS: ANÁLISE DA FUTURA UTILIZAÇÃO DA ÁGUA DO CANAL DO SERTÃO ALAGOANO
}

\author{
THE CONCEPT OF “VIRTUAL WATER” IN FOCUS INTERNATIONAL DIVISION \\ OF RISKS: ANALYSIS OF FUTURE USE OF WATER ALAGOAS HINTERLAND \\ CANAL'S
}

Juliana Lemos ${ }^{*}$

\begin{abstract}
Sumário: Introdução; 1 Noções sobre a sociedade de risco; 2 Constatações acerca do risco no centro da teoria social; 3 Ideia da divisão internacional dos riscos; 4 Água virtual: O Brasil como grande "exportador"; 5 Planos governamentais para o canal do sertão alagoano: irrigar para exportar!; Considerações finais; Referências.
\end{abstract}

\begin{abstract}
Resumo: O presente trabalho examina a idéia da água virtual, sob o enfoque da divisão internacional dos riscos, apresentando a pretensa utilização da água do Canal do Sertão Alagoano na irrigação destinada à fruticultura de exportação como meio reprodutor de tal conjuntura. Analisa como os principais teóricos das ciências sociais tratam a idéia dos riscos, bem como a sua atual relação com o direito. Observa a questão da divisão internacional dos riscos e como o conceito de "água virtual" pode ser utilizado a partir de tal concepção. No intuito de garantir a proximidade entre o estudo e a realidade local, estuda com mais detalhes a futura utilização das águas do Canal do Sertão Alagoano. Por fim, constata que a referida obra representa uma utilização inadequada do dinheiro público, visando divulgar a idéia de que o desenvolvimento da região está ligado à exportação, e assim, promover a internacionalização das águas do rio São Francisco, sem considerar os riscos ambientais e sociais de tal ação.
\end{abstract}

Palavras -chave: Sociedade de Risco. Divisão Internacional dos Riscos. Água Virtual. Canal do Sertão. Fruticultura.

\begin{abstract}
In this paper the concept of virtual water is examined under the focus of international risk sharing, presenting the alleged use of Canal do Sertão Alagoano's (Alagoas' Hinterland Canal's) water to irrigate export-grade orchards as example of a means to reproduce the concept. An analysis on how mainstream social sciences theorists approach the idea of risks, as well as how risks are currently related to Law, is carried out. Notes the issue of international risk sharing and how the concept of "virtual water" can be used in reference to it. In order to ensure proximity between this study and the local reality, the future use of the waters of the Channel Alagoas Hinterland is studied in more detail. In the end, it's verified that the Canal do Sertão Alagoano represents a misuse of public funds, solely driven to promote the idea that fruit exportation is the only way to develop the region, thus promoting the internationalization of the São Francisco river with disregard to environmental and social risks.
\end{abstract}

Key words: Risk Society. International Risk Sharing. Virtual Water. Canal do Sertão. Fruit Growing.

\section{INTRODUÇÃO}

O presente trabalho pretende estudar as bases em que se funda a "sociedade de risco", para analisar a divisão internacional dos riscos, principalmente no que concerne à questão da água virtual; bem como realizar constatações acerca de como tais averiguações podem ser aplicadas ao projeto do Canal do Sertão Alagoano.

Parece uma idéia comum mencionar a multiplicidade de riscos a que todas as pessoas estão diretamente expostas. Isto porque, envenenamento por substâncias tóxicas, assaltos, crises econômicas e uma série de outros acontecimentos são apenas uma fração dos vários riscos, mais ou menos prováveis, a que indivíduos comuns estão expostos diariamente.

Outra questão que não gera grandes discussões é considerar a exposição aos riscos como algo inerente à condição humana, tendo em vista a fragilidade da sua condição física, inevitabilidade da morte e outros riscos cotidianos.

Suscita mais controvérsias pensar nos riscos como construções sociais. Mais ousado, ainda, é considerar a idéia de "sociedade de risco", analisando-a como uma etapa subseqüente ao desenvolvimento da sociedade industrial, assim como fez Ulricht Beck (BECK, 1998).

A partir desta percepção, vários riscos são considerados "fora de controle", gerando um debate sobre a sua distribuição, emergindo, assim, a questão social e política. Neste

\footnotetext{
*Mestranda em Direito Público pala Universidade Federal de Alagoas.
} 
sentido, a questão ambiental ganha mais importância por ser evidente a emergência da questão dos riscos como problema central das sociedades contemporâneas.

Diante do atual estágio da comunidade internacional, a "sociedade de risco" também pode ser analisada através de uma relação de "exploração" por meio da divisão internacional dos riscos, com ênfase à percepção de exportação de recursos naturais incorporados a determinados produtos, assim como a questão da água virtual.

Neste sentido, no intuito de aproximar o presente estudo à realidade local, cabe a análise da utilização da água do Canal do Sertão Alagoano, tendo em vista o notório uso das águas do rio São Francisco na fruticultura irrigada para exportação, meio de internacionalização indireta dos recursos hídricos do mencionado rio.

A exposição do tema segue uma sequiência com três fases metodológicas. Primeiro, a fase exploratória, através de estudos bibliográficos; em seguida, a fase descritiva, com apontamentos relativos ao caso concreto analisado; por fim, chega-se a fase explicativa, onde há um estudo crítico da realidade observada.

O trabalho se divide em cinco tópicos. O primeiro historiciza o conceito de "sociedade de risco" e promove um debate da sua relação com o direito. O segundo demonstra como a idéia do risco deixou de ser apenas uma parte especializada da teoria social e passou a ser central. $\mathrm{O}$ terceiro tópico trata da divisão internacional dos riscos, a partir da conjuntura capitalista em que a sociedade internacional está inserida.

O quarto tópico aprofunda a análise do que seria o conceito de "água virtual", demonstrando suas implicações sociais e ecológicas. Por fim, o quinto relata o que seria o Canal do Sertão Alagoano, a partir de suas questões técnicas, aplicando, posteriormente, todos os conceitos apreendidos nos tópicos anteriores ao caso concreto.

\section{NOÇÕES SOBRE A SOCIEDADE DE RISCO E O DIREITO}

O primeiro teórico a fazer referência à "sociedade de risco" foi o sociólogo alemão Ulrich Beck em sua obra "Risk Society, towards a new modernity". Tal idéia surgiu a partir da análise de que à medida que a sociedade industrial desenvolveu-se, emergiram novos riscos, de modo que a separação entre riscos naturais, tecnológicos e sociais tornou-se permeável, tratando-se de um desafio político. Assim como pode ser observado no trecho infra: ${ }^{2}$

Com certeza, o século XX não foi pobre em catástrofes históricas: duas Guerras Mundiais, Auschwitz, Nagazaki, Harrisburg e Bhopal, agora Chernobil. Isto obriga a ser prudente na escolha das palavras e aguça a percepção para as peculiaridades históricas. Até agora, todo o sofrimento, toda a miséria, que uns seres humanos causavam a outros, se resumia a categoria dos "outros": os judeus, os negros, as mulheres, os refugiados políticos, os dissidentes, os comunistas, etc. Havia, de um lado, obstáculos, acampamentos, bairros, blocos militares e, por outro lado, as quatro paredes próprias; fronteiras reais e simbólicas, atrás das quais se poderiam excluir aqueles que aparentemente não eram afetados. Tudo isto já não existe desde Chernobil. Chegou o final dos outros, o final das nossas possibilidades de distanciamento tão sofisticadas, um final que se conheceu com a contaminação atômica. Pode-se distanciar-se a miséria, mas não os perigos da era atômica. Aí reside a nova força cultural e política desta era. Seu poder é o poder do perigo que suprime todas as zonas protegidas e todas as diferenças da modernidade. ${ }^{3}$

Num mundo mais amplo, com mais opções e participação de mais pessoas, o universo dos riscos também se amplia exponencialmente. Inicialmente, a opinião corrente era a de que embora os perigos existissem, estes seriam cada vez mais controláveis ante o avanço da ciência e tecnologia. Ocorre que a realidade demonstrou que "cada nova tecnologia, ainda que 
quando elimina os problemas, os riscos e inconveniências que fizeram com que ela fosse cogitada e implantada, cria os seus próprios". 4

Portanto, paradoxalmente, quanto mais a sociedade se expande, mais crescem os riscos em escala imprevisível. Assim, o risco passou a integrar irreversivelmente o próprio modo de ser da sociedade contemporânea. ${ }^{5}$

Luhman retoma as perplexidades identificadas por Beck, ampliando-as com bases mais pessimistas. Informando que não é possível saber previamente quais serão todos os resultados e implicações de uma decisão tomada no presente, isto é, a sociedade atual é "hipercomplexa", imperando uma série incalculável de alternativas, de modo que o futuro é sempre incognoscível apesar dos esforços de planejamento. ${ }^{6}$

Complementando estes conceitos de Luhman, De Giorgi observa que o "risco é a probabilidade de que se verifique um dano futuro que uma outra decisão teria podido evitar". Desta forma, a "observação do risco permite ver como os sistemas sociais constroem suas estratégias de absorção da incerteza". Concluindo que "a alternativa em relação ao risco não é a segurança e sim um outro risco". 7

Cabe registrar alguns pontos de grande importância na teoria de U. Beck ${ }^{8}$ :

- O perigo tem natureza híbrida, parte natural, parte causado pelo homem;

- Há pouca participação dos indivíduos nas decisões, tal fato gera sentimento de arbitrariedade, pois apesar de não participar das decisões, os indivíduos não deixam de ser atingidos pelos riscos, visto (por exemplo) que é impossível escapar de uma nuvem tóxica;

- Nem todas as causas dos perigos são perceptíveis pelos sentidos, uma vez que existem substância tóxicas invisíveis;

- "A análise retrospectiva das causas dos danos, que permitia uma decisão política fundamentada racionalmente sobre provas averiguadas, levava a aceitar uma realização dos perigos. Tratava-se de um modelo sacrifical. [...] De fato, a observação permite constatar que a vida dos pobres tem menos valor que aquela dos ricos [...]". Isto porque, à medida que idéias de proteção à saúde e ao meio ambiente opõe-se aos objetivos econômicos, observa-se o "sacrifício consciente" de vidas humanas com o fim de proteger o equilíbrio econômico. Desta forma, o valor dado à vida humana torna-se um estorvo ao desenvolvimento econômico;

- O desenvolvimento da ciência não traz um aumento da segurança, mas uma solução a certos problemas e a criação de outras dificuldades;

- O ponto de origem do dano pode estar longe do lugar da sua realização, o que aumenta o sentimento de vulnerabilidade e falta de soberania;

- Os riscos da modernidade, por causa de suas próprias estruturas, não podem ser interpretados de forma satisfatória por meio do princípio da causalidade. Tal argumento está relacionado com a discussão sobre o "universo das causas", pois a pluralidade de possíveis causas e suas interações produzem efeitos que se juntam a outras causas, produzindo novos efeitos, de modo que não é possível determinar uma relação simples entre causa e efeito;

- Além da vulnerabilidade apresentada pela noção de complexidade de causas, esta é complementada pela vulnerabilidade social e econômica.

Os pontos apresentados supra são amplamente compartilhados, contudo suas conseqüências geram divergências. Assim, para alguns, basta continuar no caminho que está sendo trilhado e os progressos técnicos permitirão resolver as dificuldades que vem sendo provocadas. Enquanto para outros, há de se mudar o sistema econômico e o modo de vida. ${ }^{9}$

No que concerne ao âmbito jurídico, o que pode ser observado é que a evolução do sistema jurídico foi baseada num posicionamento mediano, recusando-se a transformação dos 
modos de vida e dos objetivos do sistema de produção, ao mesmo tempo em que há um controle cada vez maior dos operadores científicos e econômicos. ${ }^{10}$

Para De Giorgi, "a impossibilidade de juridicizar o risco constitui o atual limite do direito". ${ }^{11}$ Neste sentido, o que se pode observar é que a estrutura clássica do Direito demonstra-se cada vez mais incapaz de fornecer respostas no que se refere à realidade dos riscos e seus desdobramentos. ${ }^{12}$

Ocorre que se o risco corresponde a um tipo de ocorrência social específica, cabe ao direito buscar soluções apropriadas que ultrapassem a noção de um improvável "direito a", para chegar à noção de garantia. Observa-se, neste ponto, uma "impotência" do direito que possui como conseqüência a manutenção do statu quo, isto é, a permanência da acumulação de riquezas como condição estruturante da sociedade. ${ }^{13}$

A saída (out-put; produto) confessada pelos organizadores do sistema é uma espécie de impotência diante dos efeitos do risco, quando, na realidade, o sistema só pode produzir a solução para a qual ele foi idealizado: se as decisões produzem riscos e os riscos produzem catástrofes, esse produto é o que o sistema reputa necessário, com ressalva de que o sistema não se fez espontaneamente: ele resulta das decisões tomadas. ${ }^{14}$

\section{CONSTATAÇÕES ACERCA DO RISCO NO CENTRO DA TEORIA SOCIAL}

Nas últimas duas décadas, o conceito de risco passou a ocupar lugar central na teoria social, tal fato decorre de dois teóricos sociais contemporâneos, Ulrich Beck, já comentado, e Anthony Giddens. Estes autores consideraram os riscos, principalmente os ambientais e tecnológicos, de graves conseqüências, como meios para entender as características, limites e transformações do projeto histórico da modernidade. ${ }^{15}$

Ambos os teóricos supra, ainda que possuam abordagens diferentes, coincidem em propor que o conceito de sociedade de risco passe a substituir o de sociedade de classes. Ocorre que enquanto Beck e Giddens projetaram o tema dos riscos ao centro da teoria social, outros autores, assim como Douglas e Wildavsky, mantiveram os riscos como um tema mais restrito de estudo, enfatizando a sua decisiva carga cultural e social. ${ }^{16}$

Mary Douglas, em sua obra Purity and danger ${ }^{17}$ (1966), formulou uma das primeiras críticas às análises técnicas dos riscos, estabelecendo as bases do que passou a ser chamado de "teoria cultural dos riscos", onde os indivíduos são organizadores ativos de suas percepções, impondo seus próprios significados aos fenômenos. Importa registrar que esta perspectiva não foi motivada pela preocupação com os riscos tecnológicos ou naturais, mas por determinados estudos antropológicos. ${ }^{18}$

Posteriormente, Douglas juntou-se a Wildavsky com o intuito de elaborar uma abordagem mais geral sobre os riscos, que também incluísse as sociedades modernas. Assim, confrontando explicações técnicas sobre os riscos, trouxeram o tema dos riscos para o campo do debate político e moral. Desta forma, na escolha dos riscos relevantes, nem sempre a evidência científica teria o papel mais importante, pelo fato de que a escolha responderia também a fatores sociais e culturais e não apenas naturais. ${ }^{19}$

Buscava-se questionar como os peritos pretendiam chegar, objetivamente, em níveis aceitáveis de segurança, ultrapassando a pergunta "o quão seguro é seguro o suficiente?"20, para chegar a seguinte questão: "o quão seguro é seguro o suficiente para esta cultura particular?" 21.22

Neste sentido, para tais autores, a atenção dada a determinados riscos em lugar de outros seria parte de um processo sócio-cultural, que dificilmente tem relação direita com o caráter objetivo dos riscos. Assim, ao considerar-se que os riscos são percebidos e 
administrados de acordo com as formas particulares de organização social, não se faz possível considerar os riscos de forma neutra, com ferramentas metodológicas quantitativas. ${ }^{23}$

\begin{abstract}
Para o hierárquico é difícil ver ameaçada a continuidade entre o presente e o futuro, imaginando que o sistema estável que protegeu as pessoas no passado, o continuará fazendo no futuro. $\mathrm{O}$ individualista tem confiança na capacidade do mercado para escolher o melhor e rejeitar o pior, o que assegurará menos riscos no futuro. Unemse ambos na aversão a riscos que representem ameaças à configuração do tecido social: invasões estrangeiras e declínio econômico. Entretanto, distanciam-se na forma em que o governo deve impor regras que afetem o comportamento dos indivíduos. $^{24}$
\end{abstract}

Beck e Giddens transformaram substancialmente o debate sobre riscos, pois ao invés de manter a análise no plano das percepções, apontam para as especificidades dos riscos contemporâneos. Desta forma, ainda que reconheçam que os riscos sempre existiram, para estes autores os atuais são objetivamente diferentes, uma vez que a sociedade contemporânea caracteriza-se pela radicalização dos princípios que orientaram o processo de modernização industrial, o que marcaria a passagem da sociedade moderna para a sociedade da alta modernidade (Giddens) ou sociedade de risco (Beck). ${ }^{25}$

Giddens $^{26}$ observa que a modernidade é uma faca de dois gumes, pois apesar das instituições sociais modernas criarem oportunidades maiores para os seres humanos gozarem de uma existência segura, também há um lado sombrio. Alguns autores, como Marx, Durkheim e Weber, ao analisar a modernidade, viram que o trabalho industrial moderno tinha conseqüências degradantes, submetendo muitos seres humanos à disciplina de um labor maçante, repetitivo. "Mas não se chegou a prever que o desenvolvimento das "forças de produção" teria um potencial destrutivo de larga escala em relação ao meio ambiente material. Preocupações ecológicas nunca tiveram muito espaço nas tradições de pensamento incorporadas na sociologia [...],27

Para Beck, ${ }^{28}$ por muito tempo, a discussão sobre as circunstâncias acerca do ar, da água e do meio ambiente, assim como sobre a destruição da natureza e do meio ambiente, em geral, ocorria predominantemente nas ciências naturais. De modo que se ignorava que as "fórmulas" das ciências naturais podem ter um significado cultural, social e político.

Segundo estes sociólogos, as sociedades altamente industrializadas, diferentemente da sociedade industrial e de classes, enfrentam riscos ambientais e tecnológicos que não são apenas efeitos colaterais do progresso, mas centrais e constitutivos destas sociedades. "Tratase de riscos cujas conseqüências, em geral de alta gravidade, são desconhecidas em longo prazo e não podem ser avaliadas com precisão". ${ }^{29}$

Transportar o tema dos riscos de uma área especializada, para levar os ricos ao centro das teorias sociais implicou na ecologização da teoria social e na interpretação sociológica das análises técnicas e quantitativas sobre os riscos. Assim, Beck e Giddens foram além da teoria cultural, ao demonstrar que são necessários novos conceitos para entender nossas sociedades. ${ }^{30}$ Isto significa que "a forma com que interpretamos os riscos, negociamos os riscos, e vivemos com as imprevisíveis conseqüências da modernidade estruturará nossa cultura, sociedade e política pelas próximas décadas". ${ }^{31}$

Giddens $^{32}$ ainda discorre sobre o que seria a intensidade do risco como o elemento básico no "aspecto ameaçador" das circunstâncias em que vivemos hoje. A intensidade global de certos tipos de risco transcende todos os diferenciais sociais e econômicos. No entanto, tal autor não olvida de mencionar que não se pode deixar de observar o fato de que muitos riscos são diferentemente distribuídos entre os privilegiados e os despossuídos.

Cumpre registrar o pensamento de Beck, ${ }^{33}$ quando afirma que os paradigmas da desigualdade social se referem sistematicamente a contextos determinados no processo de modernização. A divisão dos conflitos em torno da divisão das riquezas produzidas 
socialmente encontra-se em primeiro plano no pensamento e na atuação dos indivíduos que fazem partes do "terceiro mundo", diante da miséria trazida pela "ditadura da escassez".

Neste sentido, essas sociedades buscam o processo de modernização com a pretensão de alcançar o desenvolvimento técnico-científico para uma conseqüente riqueza social, ${ }^{34} \mathrm{sem}$, contudo, haver um direcionamento e estudo adequado quanto às possíveis consequiências deste suposto desenvolvimento.

\section{A IDEIA DA DIVISÃO INTERNACIONAL DOS RISCOS}

Para que haja o correto entendimento acerca da relação entre homem e natureza, faz-se necessária a compreensão de que existem complexas interconexões, das quais fazem parte estruturas sociais, políticas, econômicas e ideológicas, além da idéia de que as sociedades estabelecem "relações ecológicas" com o meio ambiente. ${ }^{35}$

Essas relações emergem em consonância com cada relação social, pois cada modo de produção, ao intermediar ciclos de matéria e energia, expressa nas "paisagens criadas" diferentes formas de "metabolismo" com as energias da natureza tornadas sociais. ${ }^{36}$

"O modo de produção capitalista possui uma inserção própria no quadro natural." Devendo partir de tal sistema, a busca pela compreensão e características do "retrato ecológico" mundial atual. ${ }^{37}$

O capitalismo especializou-se na articulação interna da produção e desde Adam Smith em "A riqueza das nações" (Smith, 1988) já era demonstrada a importância da divisão social do trabalho, na busca de maior produtividade e eficiência, ganhando maior especialização. " $\mathrm{E}$ esta especialização reproduziu-se espacialmente, determinando uma divisão regional (país) e internacional (planeta) do trabalho., 38

A partir das idéias expostas supra, pode-se elencar algumas características do capitalismo com certa interface ambiental: ${ }^{39}$

- A relação estabelecida entre o capital e o meio ambiente pressupõe riscos ambientais crescentes, tendo em vista um modelo de produção que necessita destruir a natureza para transformá-la em mercadoria;

- O caráter globalizado de uma economia de mercado mundial articulou uma "divisão internacional do trabalho", principalmente na relação entre Norte desenvolvido e Sul subdesenvolvido, dentro de um processo que sempre beneficiou o Norte em detrimento do Sul; sendo que não há grande diferença do ponto de vista do risco ambiental;

- Predomínio do artificial sobre o natural.

Surge a percepção da "divisão dos riscos", já que os riscos que intermedeiam a relação do capital com o meio ambiente são desigualmente distribuídos, pois estão localizados junto a segmentos subordinados e periféricos do sistema. Importa mencionar que não é apenas um processo circunscrito em "países periféricos", pois há o "primeiro mundo do terceiro" (elites abastadas) e o "terceiro mundo do primeiro" (trabalhadores imigrantes). ${ }^{40}$

Além do mais, tem-se a questão da vulnerabilidade social, pois os riscos devem ser compreendidos através do ambiente socioeconômico em que ocorrem, de modo que sistemas sócio-técnicos falíveis interagem com populações tornadas vulneráveis por meio da rápida urbanização, moradias precárias, pobreza e ausência de recursos para evitar os eventos de risco. $^{41}$

Em nível internacional, a distribuição dos riscos chama a atenção para os países do sul. Tendo em vista a transferência de "núcleos industriais poluidores para regiões de mão-de-obra barata e de farta energia e matéria-prima". Assim, a energia que está se tornando escassa nos países desenvolvidos, passa a ser incorporada nos produtos produzidos pelos países periféricos que são direcionados à exportação. ${ }^{42}$ 
Enquanto cerca de $20 \%$ da população mundial, situados principalmente nos países ricos, consome aproximadamente $80 \%$ dos bens produzidos, os outros $80 \%$, situados principalmente nos países pobres, consomem apenas 20\%. [...] Quando se considera a questão dos riscos em países como a Índia, o Brasil e o México, as posições se invertem, fazendo isso parte do próprio processo de globalização da economia. $^{43}$

Além da energia, outro insumo de importância vital para humanidade vem passando pela mesma situação, a água. Isto porque, parte significativa da água utilizada na irrigação é internacionalizada através da produção agrícola que é exportada. ${ }^{44}$

[...] muitos países pobres estão exportando enormes quantidades de água através do comércio de água virtual devido a uma necessidade desesperada de receita e porque tem sido fortemente impulsionados pelo Banco Mundial e pelo Fundo Monetário Internacional para pagar suas dívidas através da exportação de lavouras de monocultura, mesmo que isso signifique usar sua melhor e mais arável terra e o restante de seus suprimentos de água nessas plantações. ${ }^{45}$

Assim, desta percepção surge o conceito de "água virtual" que será abordado no próximo tópico.

\section{4 ÁGUA VIRTUAL: O BRASIL COMO GRANDE "EXPORTADOR"}

A água é um bem essencial para a garantia da vida humana e, portanto, possui um valor inestimável. Além de ser indispensável à produção e um recurso estratégico para o desenvolvimento, a água constitui um fator determinante na manutenção dos ciclos geológicos, biológicos e químicos que garantem equilíbrio aos ecossistemas. ${ }^{46}$

Tradicionalmente, a navegação e a produção de energia representavam os usos econômicos mais importantes da água. Isto porque não havia a consciência da possibilidade da escassez de tal insumo e, conseqüentemente, não havia preocupação com seu uso mais fundamental, isto é, para a sobrevivência humana. ${ }^{47}$

Apesar de ser antiga a noção de que a Terra possui a maior parte da sua superfície coberta por água, o conhecimento da dimensão do seu volume é recente. Mais recente é a percepção de que apenas cerca de $2,5 \%$ deste volume é constituída por água doce e, que menos de $1 \%$ está acessível para consumo humano nos rios , nos lagos e no subsolo. ${ }^{48}$

Diante deste cenário, a primeira conferência mundial significativa sobre a água ocorreu em 1977, em Mar del Plata, quando a década de 1980 foi declarada pelas Nações Unidas como a "Década Internacional de água potável e saneamento". Durante reunião preparatória para a Conferência do Rio de Janeiro, de 1992, surgiu a chamada "Declaração de Dublin", que estabeleceu quatro princípios, dos quais importa enfatizar dois: "A água doce é um recurso finito, vulnerável, essencial para a vida, desenvolvimento e para o meio ambiente" e "A água tem um valor econômico em todos os seus usos correntes e deveria ser reconhecida como um bem econômico"49

Ainda em 1992, a ONU publicou um documento intitulado "Declaração Universal dos Direitos da Água", que enuncia em seu segundo artigo:

A água é a seiva de nosso planeta. Ela é condição essencial de vida de todo vegetal, animal ou ser humano. Sem ela não poderíamos conceber como são a atmosfera, o clima, a vegetação, a cultura ou a agricultura. ${ }^{50}$

Em 2005, a Assembléia Geral da ONU publicou a Resolução n ${ }^{\circ}$ 58/217, com o objetivo de cumprir as metas do milênio no tocante à água, através da redução da metade do 
número de pessoas sem acesso à água e serviços sanitários até 2015. Neste sentido, ocorreram diversas conferências, fóruns e congressos, sendo o direito de acesso a água sempre associado à idéia de que a iniciativa privada deve ser inserida nesta tarefa, diante do destaque dado a água como bem econômico. ${ }^{51}$

Este pensamento decorre da conjunção de escassez do bem e desigualdades no acesso à água, assim, a solução apresentada por várias Organizações Internacionais, em especial a ONU, compreende atribuir valor econômico à água, com a sua transformação em mercadoria, no intuito de controlar o consumo e evitar o desperdício. "Nesse contexto, as transferências de bens entre os países tomam uma nova dimensão no sentido de levar em conta a sustentabilidade dos recursos hídricos de cada país, ao longo do tempo." ${ }^{53}$

O elemento natural escasso em um lugar e abundante em outro é um recurso. O dia em que alguém avalia esse recurso como algo a ser perdido e adquirido, ele se torna um bem; com estatuto eventual de mercadoria. ${ }^{54}$

Uma das abordagens que surgem para dimensionar economicamente as relações internacionais é a da "água virtual". A expressão virtual water (água virtual) foi cunhada pelo professor A. J. Allan no início da década de 90, que sistematizou os principais elementos do conceito, destacando a necessidade da água decorrente do crescimento populacional e do padrão de consumo de alimentos. A repercussão do termo virtual water (água virtual) passou a ser mais expressiva após a elaboração de um trabalho de identificação e quantificação de fluxos de comércio da água virtual entre os países, de modo a tornar o conceito operacional. Cabe mencionar que este trabalho foi realizado pela University of Twente (Enschede), na Holanda, e pela UNESCO-IHE Institute for Water Education. ${ }^{55}$

Em termos gerais, a água virtual deve ser observada sob a idéia do comércio indireto da água que está embutida em certos produtos, especialmente as commodities agrícolas. Assim, a água virtual pode ser conceituada como "toda água envolvida no processo produtivo de qualquer bem industrial ou agrícola", isto é, o volume em " $\mathrm{m}^{3}$ " de água necessários para a produção de " $\mathrm{x}$ " toneladas de determinada commodity. Portanto, apóia-se em um argumento simples, apesar de sua aferição empírica ser de grande complexidade. ${ }^{56}$

Independente dos diversos valores encontrados com relação ao volume anual de água virtual que é comercializada no mundo, resta claro que no comércio internacional existe um fluxo de água virtual e este fluxo é relevante para o entendimento da escassez da água e a segurança alimentar. Isto porque, a depender das relações estabelecidas, pode-se reduzir/aumentar a necessidade da água para a produção de alimentos ao importar/exportar alimentos de países ricos em água. ${ }^{57}$

Há que se ressaltar que existe uma distribuição desigual da disponibilidade hídrica no planeta além de existir variações sazonais. Neste contexto, as Américas se posicionam numa posição mais confortável, pois possuem relativa abundância de água. ${ }^{58}$

O comércio direto de água entre as nações não possui grande vulto no cenário internacional, no entanto, a água que é a absorvida e comercializada entre as nações através de seus produtos é uma realidade. Neste sentido, este comércio identifica e divide o que produzir e onde, conforme a quantidade de água disponível e necessária para a produção. Logo, este comércio visa o equilíbrio entre as nações, fornecendo uma diversidade de produtos aos países com escassez hídrica, que não poderiam ser produzidos neles sem prejuízo para o abastecimento da população. ${ }^{59}$

Um fator que chama a atenção são as diferenças nas formas de utilização da água. Constata-se que, na média, em 2006, $70 \%$ da água era utilizada pelo setor agrícola, $20 \%$ pelas indústrias e $10 \%$ para uso doméstico. No entanto, se verificarmos a mesma tabela, as formas de utilização entre os continentes são diferentes, enquanto a Europa e América do Norte utilizam um pouco mais de $30 \%$ dos recursos hídricos no setor agrícola, na África o 
percentual atinge $86 \%$ e na Ásia $81 \%$. Segue a América do Norte que utiliza $13,7 \%$ do volume total de água doce e se destacada, quantitativamente e percentualmente no setor industrial. Logo a seguir, vem a Europa com 10,9\% da água total, da qual 53\% (223 km3) destinados à industria. ${ }^{60}$

Tais formas de utilização da água refletem a especialização dos países que participam das trocas internacionais. Neste sentido, os países que tem na agricultura seu principal setor econômico utilizam grande quantidade de água virtual, ${ }^{61}$ como é o atual caso do Brasil.

O Brasil ocupa, no atual mercado internacional, uma importante posição na exportação de soja, carne, açúcar e frutas tropicais. Isto porque possui grande disponibilidade de terras cultiváveis e de recursos hídricos, além dos baixos custos de produção. No entanto, em termos ambientais, tal fato significa a transferência de um recurso ambiental (a água), que o Brasil tem em grande quantidade, para países que não dispõem deste recurso. ${ }^{62}$

Ocorre que as conseqüências de um comércio orientado por abundância ou escassez de água podem ser danosas. No Brasil, a disponibilidade de água é mais concentrada na Região Norte do país, assim, observa-se a expansão da produção de soja em direção a tal região, que também abriga importantes remanescentes florestais e rica biodiversidade. Portanto, tal formato de "divisão de produção" torna-se contrário à preservação da região. ${ }^{63}$

Desta forma, possuir água em abundância e terras a baixo preço não podem ser os únicos fatores determinantes na substituição de determinados ecossistemas por pastagens ou grandes plantações. A questão não é a agricultura ou a expansão da pecuária, pois são atividades economicamente importantes para o país, mas a forma altamente impactante que essas atividades possuem. ${ }^{64}$

Daí a idéia de uma visão holística dos recursos hídricos, de modo a abarcar suas faces econômica, política, social e ambiental, levando-se em consideração a segurança hídrica para a população e condições de produção industrial e agrícola para outros setores. ${ }^{65^{5}}$

Muitos países pobres estão exportando tanto volume de água que se encaminham em direção à seca. Entre 15 e $20 \%$ da água usada no mundo para propósitos humanos são utilizados para exportação. Com a ênfase dada pelo Banco Mundial e outras instituições financeiras globais ao crescimento das exportações, a transferência de água dos países pobres para os ricos deve aumentar, e com ela, os riscos da ausência da água para, até mesmo, a sobrevivência humana. ${ }^{66}$

Destarte, considerar a água como produto de exportação indireta brasileira, sob o conceito de água virtual, nos remete ao já debatido processo de divisão internacional dos riscos, "pois evidencia quem está pagando a conta da escassez dos recursos hídricos de outras regiões do mundo". Podendo ser concluído que "quando os limites da modernidade atingem os patamares da escassez, mudam as ameaças a que estamos expostos". 67

\section{PLANOS GOVERNAMENTAIS PARA O CANAL DO SERTÃO ALAGOANO: IRRIGAR PARA EXPORTAR!}

O Canal do Sertão Alagoano integra as ações de recursos hídricos do Programa de Aceleração do Crescimento - PAC, do Governo Federal; tal empreendimento está em construção desde 1991. A obra aduzirá $32 \mathrm{~m}$ 3/s de água do rio São Francisco em sua fase final, já tendo recebido da Agência Nacional de Águas - ANA a outorga prévia de $3,6 \mathrm{~m} / \mathrm{s}$ para a sua primeira etapa. ${ }^{68}$

Desta forma, a estação elevatória tem capacidade para bombear $32 \mathrm{~m}^{3} / \mathrm{s}$, sendo composta por 12 conjuntos de bombeamento de $2000 \mathrm{CV}$, cada um com capacidade para bombear $2,67 \mathrm{~m}^{3} / \mathrm{s}^{69}$

A partir do quilômetro zero, o canal se estenderá por $250 \mathrm{~km}$ ao longo do sertão alagoano até o município de Arapiraca, abastecendo 42 municípios, de modo que o sistema 
atenderá a uma área de aproximadamente $13.200 \mathrm{Km}^{2}$, o que representa $48 \%$ da área do Estado. $^{70}$

Trata-se da maior obra hídrica do Governo do Estado de Alagoas, cujos custos de implantação estão orçados em $\mathrm{R}$ \$ 620 milhões, já tendo sido efetivados R \$265,8 milhões até março de 2008, segundo relatório do PAC. ${ }^{71}$

O Canal do Sertão Alagoano foi concebido com base em objetivos sociais, culturais, econômicos e ambientais.

Socialmente, o projeto visa melhorar o nível de vida da população rural, implantando infra-estrutura social na zona rural. No âmbito cultural, a idéia é transferir tecnologia mais adequada às condições naturais da região. Economicamente, pretende-se dar condições para que a população desenvolva atividades econômicas sustentáveis, enquanto, ambientalmente, busca-se diminuir as atividades extrativistas desordenadas. ${ }^{72}$

Segundo o atual Governador do Estado, o Canal do Sertão tem como prioridade a geração de emprego e renda, com a utilização integrada do rio São Francisco na irrigação, na piscicultura, na pecuária e na agroindústria das regiões do sertão e semi-árido, além da sua utilização para o abastecimento de água às populações das regiões não atendidas por outros sistemas. $^{73}$

Para cumprir o objetivo da pesquisa de analisar como será utilizada a água do Canal do Sertão Alagoano, fez-se necessário buscar junto ao Governo do Estado quais são as diretrizes que estão sendo concretamente estimuladas. Visto que a orientação aos possíveis beneficiados pelo projeto será dada por tal ente.

Apesar da falta de publicidade quanto a questões de grande importância relativas ao Canal, assim como os critérios utilizados para a outorga do uso da água e o meio de desapropriação das propriedades e indenização das famílias que precisaram e precisarão ser deslocadas para a passagem do Canal.

Tendo em vista que para a construção do Canal do Sertão, ao menos 200 famílias precisarão ser deslocadas; recebendo possíveis indenizações com recurso do Governo Federal, apenas as que possuem as terras devidamente registradas em cartório, o que representa um grande problema social, uma vez que é notório que a maior parte das propriedades no sertão nordestino é de apenas possuidores e não proprietários. Também há a questão de que já foram construídos $45 \mathrm{Km}$ do Canal, concluindo-se assim sua primeira etapa, contudo pouco é divulgado sobre a forma como esta água beneficiará a agricultura familiar local; isto porque não há publicidade no tocante aos critérios utilizados para a escolha das famílias que deverão ocupar os lotes beneficiados pelo projeto.

Mesmo com toda a problemática apresentada supra no tocante à divulgação de questões de suma importância quanto ao Canal do Sertão, já pode ser encontrada a disposição dos sertanejos, assim como, na grande mídia, através da internet, cartilha divulgada pelo Governo do Estado com o objetivo de expor as suas diretrizes quanto a questões de desenvolvimento econômico e do uso da água do Canal.

A mencionada cartilha expõe imediatamente seu objetivo central, visto que foi intitulada como: "fruticultura". Assim, demonstra o interesse do Estado em atrair "empreendimentos" voltados ao desenvolvimento da fruticultura irrigada, principalmente, manga, pinha, graviola, melão, maracujá e laranja na região do sertão e semi-árido. Inclusive com incentivos fiscais, creditícios e locacionais do Governo estadual; ${ }^{74}$ além de expor questões estatísticas e econômicas da fruticultura irrigada para exportação no Brasil e no Nordeste, especificamente, mencionado regiões exemplo de "sucesso" em tal empreendimento. Por fim, afirma-se que o Canal do Sertão irá aumentar a área irrigada, que também deverá ser utilizada com este fim. ${ }^{75}$

Não é apenas em tal cartilha que se encontra definida a fruticultura como um dos mais importantes usos a que será destinada à água do Canal do Sertão, mas em todas as 
informações do Governo sobre a obra. Inclusive no site do Ministério da Integração, onde o projeto do Canal do Sertão Alagoano está vinculado ao Programa de Desenvolvimento da Agricultura Irrigada. ${ }^{76}$

Importa registrar que é notório o conhecimento de que parte significativa da água do rio São Francisco já é utilizada para a irrigação de uma produção agrícola destinada à exportação, principalmente, para a população européia. ${ }^{77}$ Assim, o que se observa é que a construção da obra do Canal do Sertão visa, principalmente, reproduzir uma utilização inadequada das águas do rio São Francisco.

Isto porque a fruticultura irrigada naturalmente despende um volume grande de água, no entanto, quando tais culturas são empregadas em ambientes com o sertão ou o semi-árido, a quantidade de água se torna ainda maior. De todos os possíveis usos da água doce, como higiene, alimentação, transporte, lazer e processos produtivos industriais, comerciais e agrícolas, os usos agrícolas são os que requerem maior volume de água. ${ }^{78}$

Como já foi mencionado, de um modo geral no mundo, cerca de $70 \%$ de toda água retirada dos rios ou do subsolo é usada para irrigação; enquanto apenas $20 \%$ se destina para usos industriais e $10 \%$ para usos residenciais. Há de se acrescentar ainda, a maior exigência relativa em termos de qualidade da água requerida para a agricultura irrigada, além deste uso ser altamente "consumptivo", isto é, um uso em que grande parte ou o total da água captada não retorna aos mananciais de origem. ${ }^{79}$

Assim, constata-se a construção de uma obra faraônica, em que será empregado um grande montante de dinheiro público, com o intuito de captar parte da água de um rio (São Francisco), que já se encontra com grandes dificuldades, sem que sejam levados em consideração os impactos que poderão ser causados com tal transposição.

Como exemplo de situação semelhante já ocorrida, pode ser observada a água desviada do Mar de Aral através de um canal dragado e enviado para o deserto com o objetivo de cultivar algodão. Há época, 60 anos atrás, o Mar de Aral era o quarto maior lago do mundo, atualmente, perdeu mais de $80 \%$ de seu volume e o que restou foi uma água extremamente salgada. Assim como ocorre com o Lago Chad que foi o sexto maior lago do mundo e já não existe mais. ${ }^{80}$

Além desses graves fatores, um dos principais usos a que se destina o desvio da água do rio São Francisco será o da agricultura irrigada para fruticultura com o objetivo de exportação. Isto é, busca-se levar a água do rio São Francisco para outras localidades do Estado com o intuito de garantir mais áreas exportadoras de água virtual. O que gera o uso desordenado e inapropriado das águas do rio, ocasionando a médio e longo prazo o risco de aumentar a escassez através da degradação do mesmo. Tal situação não se opera apenas no sertão e semi-árido nordestino, mas também no restante do país, uma vez que tal incentivo exportação de água virtual ocorre em diversas regiões.

Desta forma, pretende-se degradar o rio São Francisco, exportando grande parte de seus recursos hídricos, principalmente, através de frutas.

Portanto, constata-se a utilização inadequada dos recursos naturais. Isto porque, para a sobrevivência da população sertaneja no nordeste não há necessidade da construção de quaisquer Canais. Uma vez que a quantidade de água precipitada somada às águas de superfície, principalmente dos rios São Francisco e Parnaíba, e às águas de subsolo, faz com a região seja perfeitamente viável para vida humana. Entretanto, a infra-estrutura de armazenamento da água da chuva é capaz de armazenar apenas 36 bilhões de metros cúbicos. Assim, aproximadamente 720 bilhões de metros cúbicos são desperdiçados por ano. ${ }^{81}$

Por fim, resta mencionar que apesar da economia do semi-árido estar operando à margem de um sistema educativo e social, em geral, precário, tal fato não decorre da falta da passagem do rio São Francisco ou da falta da economia voltada à exportação, mas da ausência 
de formulação de planos de aproveitamento dos recursos naturais, de modo a contemplar as transformações socioeconômicas e ambientais produzidas. ${ }^{82}$

Devendo-se buscar a o melhor aproveitamento dos recursos hídricos existentes e o cultivo de culturas adequadas à região, sem o uso exacerbado da água na irrigação de culturas com viés de exportação, o que coloca em risco o ecossistema local e regional.

\section{CONSIDERAÇÕES FINAIS}

O trabalho analisou a idéia da água virtual, sob o enfoque da divisão internacional dos riscos, apresentando a pretensa utilização da água do Canal do Sertão Alagoano na irrigação destinada à fruticultura de exportação, como meio reprodutor de tal conjuntura.

Foram mencionados os principais autores que influenciaram a idéia de sociedade de risco, demonstrando uma mudança na visão das ciências sociais, isto é, uma preocupação que ultrapassa questões culturais e que começa a preocupar-se com as conseqüências ambientais da sociedade moderna.

Enquadrando tal pensamento no contexto capitalista em que se encontra grande parte dos países, passou-se a analisar a divisão internacional dos riscos, trazendo como um dos expoentes desta percepção a idéia da água virtual. Isto porque diante do cenário mundial atual de escassez de água doce, a exportação da água virtual gera grandes riscos de faltar água para a população dos países pobres.

O estudo do conceito de água virtual, bem com a constatação da sua concretização, demonstrou como as problemáticas relativas à escassez da água estão sendo tratadas de modo inadequado, sem a devida precaução e análise cuidadosa dos riscos ambientais.

Apesar de não ser uma utilização usual da idéia de riscos, pois não se refere a riscos radioativos ou semelhantes, possui extrema importância porque é fato que o mundo está ficando sem água doce e sem esta não há sobrevivência humana, importando observar que a escassez vem sendo ampliada pelo uso humano inadequado da água na agricultura e indústria. Assim, o risco da ausência de água representa uma realidade que pode ser expandida pelo uso impróprio dos recursos hídricos.

Após a compreensão dos riscos apresentados pela exportação indireta da água, observou-se a implantação do Canal do Sertão Alagoano, o qual busca transpor parte da água do rio São Francisco com objetivos de implementar a fruticultura de irrigação para exportação. Demonstrando uma falta de compreensão das autoridades públicas locais e nacionais quanto aos problemas de escassez de recursos hídricos em nível mundial.

Por fim, constata-se dentro do contexto da divisão internacional dos riscos ambientais, o processo de internacionalização das águas do rio São Francisco, através da desmesurada construção de obras que apesar de proporem-se a garantir o desenvolvimento da região do sertão e semi-árido, na verdade, constituem práticas inadequadas a um desenvolvimento sustentável da região, gerando o risco de degradação do rio São Francisco.

\section{REFERÊNCIAS}

\section{BARLOW, Maude. Água, Pacto Azul. A crise global e a batalha pelo controle da água potável no mundo. São Paulo: M. Books, 2009.}

BECK, Ulrich. La sociedad del riesgo: hacia una nueva modernidad. Barcelona: Paidós, 1998. 
Brasil. Ministério da Integração Nacional. Disponível em:

$<$ http://www.integracao.gov.br/programas/infraestruturahidrica/index.asp?area=sih_desenvolv imento_canal_alagoano>. Acesso em 23 de maio de 2011.

BRZEZINSKI. Maria Lucia Navarro. Água Doce no Século XXI: serviço público ou mercadoria internacional? São Paulo: Lawbook, 2009.

CARMO, Roberto Luiz do; OJIMA, Andrea Leda Ramos de Oliveira; OJIMA, Ricardo; NASCIMENTO, Thais Tartalha do. Água virtual, escassez e gestão: o Brasil como grande “exportador” de água. Ambiente e Sociedade, Campinas, vol. X, ano 1, jan-jun 2007,

CAUBET, Christian G. A água doce nas relações internacionais. Barueri: Manole, 2006.

CAUBET, Christian Guy. Antes e depois do dano: da decisão arriscada à certeza do prejuízo. In: VARELLA, Marcelo. Direito, Sociedade e Riscos: a sociedade contemporânea vista a partir da idéia do risco. Brasília: Uniceub, 2006.

DOUGLAS, Mary. Purity and danger. An analysis of conceptions of polution and taboo. Londres: Routledge, 1966.

Estado de Alagoas. Agronegócios. Fruticultura. Disponível em:

<http://www.investimentosalagoas.al.gov.br/op/ag_02.pdf>. Acesso em 23 de maio de 2011.

FAIÃO, Daniel; SORGATO, João; PEDROSA, Valmir de Albuquerque Pedrosa. Canal do Sertão Alagoano: o custo da energia elétrica. Disponível em:

<http://www.ctec.ufal.br/professor/vap/CustoEnergiaCanalAlagoano.pdf >. Acesso em $23 \mathrm{de}$ maio de 2011.

FRANKLIN, Jane. Introduction. In Franklin, Jane (ed.), The politics of the risk society. Cambridge: Polity Press, 1998.

FREITAS, Carlos Machado; PORTO, Marcelo Firpo de Souza. Industria química brasileira, acidentes químicos ampliados e vulnerabilidade social. In: COSTA, Heloisa; TORRES, Haroldo. Poluição e meio ambiente: debates e desafios. 2 ed. São Paulo: SENAC, 2006.

FREITAS, Wladimir Passos de. Águas: aspectos jurídicos e ambientais. 2 ed. Curitiba: Juruá, 2007.

GIDDENS, Anthhony. As conseqüências da modernidade. São Paulo: UNESP, 1991.

GIORGI, Raffaele de. Direito, democracia e risco: vínculos com o futuro. Porto Alegre: Sergio Antonio Fabris, 1998.

GODOY, Amália Maria Goldberg; LIMA, Adriano José de. Água virtual e comércio internacional desigual. p. 2 Disponível em:

$<$ http://www.economiaetecnologia.ufpr.br/XI_ANPEC-Sul/artigos_pdf/a4/ANPEC-Sul-A403-agua_virtual_e_comercio_.pdf>.Acesso em 23 de maio de 2011. 
GUIVANT, Julia S. A trajetória das análises de risco: da periferia ao centro da teoria social. p. 1. Disponível em: 〈http://www.iris.ufsc.br/pdf/trajetoriasdasanalisesderisco.pdf >. Acesso em 23 de maio de 2011.

HERMITE. M-A. Os fundamentos jurídicos da sociedade de risco: uma análise de U. Beck. In: VARELLA, M. D. (org.) Governo dos riscos. Brasília: Rede Latino-Americana-Européia, 2005, p. 11-40.

LEMOS, Marco Antônio da Silva. O direito como regulador da sociedade de riscos. In: VARELLA, Marcelo. Direito, Sociedade e Riscos: a sociedade contemporânea vista a partir da idéia de risco. Brasília: Uniceub, 2006.

RODRIGUES, Geraldo Stachetti. IRIAS, Luis Jose Maria. Considerações sobre os Impactos Ambientais da Agricultura Irrigada. Circular Técnica, Jaquariúna: EMBRAPA, 2004.

VIEIRA, Leonardo Lopes de Azevedo; BARROS, Thaís Tonin de; PIMENTEL, Irene $\mathrm{M}^{\mathrm{a}}$ Chaves; FAIÃO, Daniel; PEDROSA, Valmir de Albuquerque Pedrosa. A futura oferta da água pelo canal do sertão alagoano. Disponível em: < http://www.ctec.ufal.br/professor/vap/OfertadeaguapeloCanal.pdf $>$. Acesso em 23 de maio de 2011.

VILELA FILHO, Teotônio. A água e o futuro da humanidade. Brasília: Senado Federal, 2003.

WALDMAN, Maurício. Ecologia e lutas sociais no Brasil. 6 ed. São Paulo: Contexto, 2002.

Organização das Nações Unidas (ONU). Declaração Universal dos Direitos da Água.

Disponível em: <http://www.onu-brasil.org.br> . Acesso em 23 de maio de 2011.

\footnotetext{
${ }^{1}$ Tradução Livre: Sociedade de Risco, em direção a uma nova modernidade.

${ }^{2}$ HERMITE. M-A. Os Fundamentos Jurídicos da Sociedade de Risco: uma análise de U. Beck. In:

VARELLA, M. D. (org.) Governo dos riscos. Brasília: Rede Latino-Americana-Européia, 2005, p. 11-40.

${ }^{3}$ BECK, Ulrich. La sociedad del riesgo: hacia una nueva modernidad. Barcelona: Paidós, 1998. p. 11.

Tradução Livre: En verdad, el siglo xx no ha sido pobre en catástrofes históricas: dos guerras mundiales, Auschwitz, Nagasaki, luego Harrisburg y Bhopal, ahora Chemobil. Esto obliga a ser prudente en la elección de las palabras y agudiza la mirada para las peculiaridades históricas. Hasta ahora, todo el sufrimiento, toda la miseria, toda la violencia que unos seres humanos causaban a otros se resumía bajo la categoría de los «otros»: los judíos, los negros, las mujeres, los refugiados políticos, los disidentes, los comunistas, etc. Había, por una parte, vallas, campamentos, barrios, bloques militares, y, por otra parte, las cuatro paredes propias; fronteras reales y simbólicas tras las cuales podían retirarse quienes en apariencia no estaban afectados. Todo esto ya no existe desde Chemobil. Ha llegado el final de los otros, el final de todas nuestras posibilidades de distanciamiento, tan sofisticadas; un final que se ha vuelto palpable con la contaminación atómica. Se puede dejar fuera la miseria, pero no los peligros de la era atómica. Ahí reside la novedosa fuerza cultural y política de esta era. Su poder es el poder del peligro que suprime todas las zonas protegidas y todas las diferenciaciones de la modernidad.

${ }^{4}$ LEMOS, Marco Antônio da Silva. O direito como regulador da sociedade de riscos. In: VARELLA, Marcelo. Direito, Sociedade e Riscos: a sociedade contemporânea vista a partir da idéia de risco. Brasília: Uniceub, 2006. p. 325.

${ }^{5}$ Idem.

${ }^{6}$ Idem. p. 327.

${ }^{7}$ DE GIORGI, Raffaele. Direito, democracia e risco: vínculos com o futuro. Porto Alegre: Sergio Antonio Fabris, 1998. p. 14.

${ }^{8}$ HERMITE. M-A. Os Fundamentos Jurídicos da Sociedade de Risco: uma análise de U. Beck. In: VARELLA, M. D. (org.) Governo dos riscos. Brasília: Rede Latino-Americana-Européia, 2005, p. 11-40.

${ }^{9}$ Idem. p. 4
} 
${ }^{10}$ Idem.

${ }^{11}$ DE GIORGI, Raffaele. Op. Cit. p. 14.

12 LEMOS, Marco Antônio da Silva. Op. Cit. p. 329

${ }^{13}$ CAUBET, Christian Guy. Antes e depois do dano: da decisão arriscada à certeza do prejuízo. In: VARELLA, Marcelo. Direito, Sociedade e Riscos: a sociedade contemporânea vista a partir da idéia do risco. Brasília: Uniceub, 2006. p. 320,

${ }^{14}$ Idem.

${ }^{15}$ GUIVANT, Julia S. A trajetória das análises de risco: da periferia ao centro da teoria social. p. 1.

Disponível em: <http://www.iris.ufsc.br/pdf/trajetoriasdasanalisesderisco.pdf>. Acesso em: 15 de maio de 2011.

${ }^{16}$ Idem.

${ }^{17}$ DOUGLAS, Mary. Purity and danger. An analysis of conceptions of polution and taboo. Londres:

Routledge, 1966.

${ }^{18}$ GUIVANT, Julia S. Op. Cit. p. 3/4.

19 Idem. p. 4.

${ }^{20}$ Tradução Livre: how safe is safe enough?

21 Tradução Livre: how safe is safe enough for this particular culture?

${ }^{22}$ GUIVANT, Julia S. Op. Cit. p. 4.

23 Idem. p. 5.

${ }^{24}$ Idem.

25 Idem. p. 18

${ }^{26}$ GIDDENS, Anthhony. As conseqüências da modernidade. São Paulo: UNESP, 1991. p. $16 / 17$.

${ }^{27}$ GUIVANT, Julia S. A trajetória das análises de risco: da periferia ao centro da teoria social. p. 17.

Disponível em: <http://www.iris.ufsc.br/pdf/trajetoriasdasanalisesderisco.pdf>. Acesso em: 15 de maio de 2011 .

${ }^{28}$ BECK, Ulrich. La sociedad del riesgo: hacia una nueva modernidad. Barcelona: Paidós, 1998. p. 30.

${ }^{29}$ Idem. p. 19

${ }^{30}$ Idem. p. $34 / 35$.

${ }^{31}$ Franklin, Jane. Introduction. In Franklin, Jane (ed.), The politics of the risk society. Cambridge: Polity Press, 1998. p. 1.

${ }^{32}$ GIDDENS, Anthhony. Op. Cit. p. 127/128.

${ }^{33}$ BECK, Ulrich. Op. Cit. p. 26.

34 Idem.

${ }^{35}$ WALDMAN, Maurício. Ecologia e lutas sociais no Brasil. 6 ed. São Paulo: Contexto, 2002. p. 18.

${ }^{36}$ Idem.

${ }^{37}$ Idem. p. 19

${ }^{38}$ Idem.

${ }^{39}$ Idem. p. 19/20.

${ }^{40}$ Idem. p. 21.

${ }^{41}$ FREITAS, Carlos Machado; PORTO, Marcelo Firpo de Souza. Industria química brasileira, acidentes químicos ampliados e vulnerabilidade social. In: COSTA, Heloisa; TORRES, Haroldo. Poluição e meio ambiente: debates e desafios. 2 ed. São Paulo: SENAC, 2006. p. 312.

${ }^{42}$ WALDMAN, Maurício. Ecologia e lutas sociais no Brasil. 6 ed. São Paulo: Contexto, 2002. p. 21.

${ }^{4}$ FREITAS, Carlos Machado; PORTO, Marcelo Firpo de Souza. Op. Cit. p. 312.

${ }^{44}$ CAUBET, Christian G. A água doce nas relações internacionais. Barueri: Manole, 2006. p. 46.

${ }^{45}$ BARLOW, Maude. Água, Pacto Azul. A crise global e a batalha pelo controle da água potável no mundo. São Paulo: M. Books, 2009. p.29.

${ }^{46}$ DE FREITAS, Wladimir Passos. Águas: aspectos jurídicos e ambientais. 2 ed. Curitiba: Juruá, 2007. p. 50.

${ }^{47}$ CAUBET, Christian G. A água doce nas relações internacionais. Barueri: Manole, 2006. p. XIX.

${ }^{48}$ DE FREITAS, Wladimir Passos. Op. Cit. p. 50.

${ }^{49}$ Idem. p. 63.

${ }^{50}$ Organização das Nações Unidas (ONU). Declaração Universal dos Direitos da Água. Disponível em:

<http://www.onu-brasil.org.br> Acesso em: 01 de novembro de 2010.

${ }^{51}$ BRZEZINSKI. Maria Lucia Navarro. Água Doce no Século XXI: serviço público ou mercadoria internacional? São Paulo: Lawbook, 2009. p. 64.

52 Idem. p. 57.

${ }^{53}$ GODOY, Amália Maria Goldberg; LIMA, Adriano José de. Água virtual e comércio internacional desigual. p. 2 Disponível em: <http://www.economiaetecnologia.ufpr.br/XI_ANPEC-Sul/artigos_pdf/a4/ANPEC-Sul-A403-agua_virtual_e_comercio_.pdf $>$. Acesso em : 01 de novembro de 2010.

${ }^{54}$ BRZEZINSKI. Maria Lucia Navarro. Op. Cit. p. 48. 
${ }^{55}$ CARMO, Roberto Luiz do; OJIMA, Andrea Leda Ramos de Oliveira; OJIMA, Ricardo; NASCIMENTO, Thais Tartalha do. Água virtual, escassez e gestão: o Brasil como grande "exportador” de água. Ambiente e Sociedade, Campinas, vol. X, ano 1, jan-jun 2007, p. 83.

${ }^{56}$ Idem. p. 84.

${ }^{57}$ GODOY, Amália Maria Goldberg; LIMA, Adriano José de. Op. Cit, p. 4.

${ }^{58}$ CARMO, Roberto Luiz do; OJIMA, Andrea Leda Ramos de Oliveira; OJIMA, Ricardo; NASCIMENTO, Thais Tartalha do. Op. Cit.. p. 86.

${ }^{59}$ Idem. p. 90.

${ }^{60}$ GODOY, Amália Maria Goldberg; LIMA, Adriano José de. Op. Cit, p. 8.

${ }^{61}$ Idem. p. 10.

${ }^{62}$ CARMO, Roberto Luiz do; OJIMA, Andrea Leda Ramos de Oliveira; OJIMA, Ricardo; NASCIMENTO, Thais Tartalha do. Op. Cit. p. 83.

${ }^{63}$ Idem. p. 91.

${ }^{64}$ Idem.

${ }^{65}$ Idem.

${ }^{66}$ BARLOW, Maude. Água, Pacto Azul. A crise global e a batalha pelo controle da água potável no mundo. São Paulo: M. Books, 2009. p. 30.

${ }^{67}$ CARMO, Roberto Luiz do; OJIMA, Andrea Leda Ramos de Oliveira; OJIMA, Ricardo; NASCIMENTO,

Thais Tartalha do. Op. Cit. p. 93.

${ }^{68}$ FAIÃO, Daniel; SORGATO, João; PEDROSA, Valmir de Albuquerque Pedrosa. Canal do Sertão Alagoano: o custo da energia elétrica. Disponível em:

<http://www.ctec.ufal.br/professor/vap/CustoEnergiaCanalAlagoano.pdf > Acesso em: 23 de maio de 2011.

${ }^{69}$ Idem.

${ }^{70}$ Idem.

${ }^{71}$ Idem.

${ }^{72}$ VIEIRA, Leonardo Lopes de Azevedo; BARROS, Thaís Tonin de; PIMENTEL, Irene M ${ }^{\text {a }}$ Chaves; FAIÃO, Daniel; PEDROSA, Valmir de Albuquerque Pedrosa. A futura oferta da água pelo canal do sertão alagoano. Disponível em: < http://www.ctec.ufal.br/professor/vap/OfertadeaguapeloCanal.pdf > Acesso em: 23 de maio de 2011.

${ }^{73}$ VILELA FILHO, Teotônio. A água e o futuro da humanidade. Brasília: Senado Federal, 2003. p. 31.

${ }^{74}$ Estado de Alagoas. Agronegócios. Fruticultura. Disponível em:

<http://www.investimentosalagoas.al.gov.br/op/ag_02.pdf >. Acesso em: 24 de maio de 2011.

${ }^{75}$ Idem.

${ }^{76}$ Brasil. Ministério da Integração Nacional. Disponível em:

<http://www.integracao.gov.br/programas/infraestruturahidrica/index.asp?area=sih_desenvolvimento_canal_alag oano>. Acesso em: 14 de maio de 2011.

${ }^{77}$ CAUBET, Christian G. A água doce nas relações internacionais. Barueri: Manole, 2006. p. 46.

${ }^{78}$ RODRIGUES, Geraldo Stachetti. IRIAS, Luis Jose Maria. Considerações sobre os Impactos Ambientais da Agricultura Irrigada. Circular Técnica, Jaquariúna: EMBRAPA, 2004. p. 2.

${ }^{79}$ Idem.

${ }^{80}$ BARLOW, Maude. Água, Pacto Azul. A crise global e a batalha pelo controle da água potável no mundo. São Paulo: M. Books, 2009. p. 38.

${ }^{81}$ VIEIRA, Leonardo Lopes de Azevedo; BARROS, Thaís Tonin de; PIMENTEL, Irene M ${ }^{\text {a }}$ Chaves; FAIÃO, Daniel; PEDROSA, Valmir de Albuquerque Pedrosa. A futura oferta da água pelo canal do sertão alagoano. Disponível em: < http://www.ctec.ufal.br/professor/vap/OfertadeaguapeloCanal.pdf > Acesso em: 23 de maio de 2011.

${ }^{82}$ Idem. 